УДК 005.334(075.8)

\title{
ВОЗМОЖНЫЕ СЦЕНАРИИ УПРАВЛЕНИЯ РИСКАМИ ПРОМЫШЛЕННЫХ ПРЕДПРИЯТИЙ
}

\section{Т.Ф. МАНЦЕРОВА}

канд. экон. наук, заведующий кафедрой «Экономика и организация энергетики» Белорусского национального технического университета, г. Минск

\author{
Е.И. ТЫМУЛЬ \\ аспирант
}

Белорусского национального технического университета, г. Минск

\section{Аннотация}

В статье рассмотрень существующие модели управления рисками. Уточнены их преимущества и недостатки. На основе анализа моделей предложен авторский вариант модели управления рисками. Уточнены возможные риски для предприятий энергетики Республики Беларусь при переходе к рынку энергии и мощњности.

Ключевые слова: риск, отраслевая специфика рисков, энергетика, прочесс управления рисками, модель.

The existing risk management models are examined in the article. Their advantages and disadvantages are clarified. The author's model of the operational risk management on the basis of the model analysis is proposed. The possible risks for energy companies of the Republic of Belarus in case of the transition to the electric power market are specified.

Keywords: risk, industry-specific risk, Energetics, risk management process, model.

\section{ВВЕДЕНИЕ}

Современные экономические условия имеют тенденцию к постоянной изменчивости, что открывает для предприятий различные возможности, но, в тоже время, приводит к ряду сложных моментов, которые практически невозможно преодолеть при традиционных подходах к менеджменту хозяйственной деятельности. Таким образом, для адаптации к рыночным условиям и повышению конкурентоспособности предприятию необходимо научиться управлять хозяйственной деятельностью в условиях неопределенности и риска.

\section{РЕЗУЛЬТАТЫ И ИХ ОБСУЖДЕНИЕ}

Существуют различные авторские подходы как в понимании содержания термина «риск», так и в понимании природы рисков. Можно выделить три основные точки зрения, признающие различную природу возникновения рисков:

1) Субъективная природа: риск связан с выбором определенных альтернатив, расчетом вероятностей их исхода. Кроме того, люди по-разному воспринимают одну и ту же величину экономического риска в связи с различиями психологических и нравственных принципов и установок.

2) Объективная природа: обусловливает случайный характер многих природных, социальных и технологических процессов. Объективность риска проявляется в том, что это понятие отражает только реально существующие в жизни явления и процессы, то есть риск существует независимо от того, осознают его наличие или нет.

3) Субъективно-объективная природа: риск порождается как процессами субъективного характера, так и процессами, которые не зависят от воли и сознания человека.

Стоит отметить, что в работах современных авторов преобладает именно субъективно-объективная природа возникновения рисков предприятий $[3,4,5]$.

В результате неопределенности условий, в которых осуществляется современная хозяйственная деятельность, предприятия изначально лишены однозначно заданных 
параметров, обеспечивающих их успех. Таким образом, деятельность любого предприятия, работающего в рыночных условиях, будет связана с проявлением различных рисков. При этом, отраслевая специфика и особенности технологического процесса будут в значительной мере влиять на величину того или иного риска.

Энергетика - это один из основных видов экономической деятельности, в результате которой генерируется и передается тепловая и электрическая энергия необходимая не только для функционирования любого предприятия, а также для обеспечения жизнедеятельности населения.

Предстоящие изменения в энергетике Республики Беларусь предполагают дальнейшую деятельность энергетических предприятий в условиях создаваемого конкурентного рынка энергии и мощности, а новые правила рынка, в свою очередь, приведут к возникновению различных рисков.

Если говорить о чистых рисках, то наибольшее значение для энергетических предприятий могут иметь природно-естественные, транспортные и производственные риски, так как каждый из этих рисков может привести к перебоям в работе предприятия энергетики, что, в свою очередь, вызовет сбои в работе предприятий реального сектора экономики и ЖКХ.

Тем не менее, основное внимание энергетическим предприятиям необходимо обратить непосредственно на финансовые риски. Это обусловлено отсутствием в достаточном количестве запасов топлива, что приводит к зависимости отрасли от импортируемого топлива, оплата за которое производится в иностранной валюте. Следовательно, валютный риск имеет огромное значение для функционирования предприятий энергетики.

Существующий порядок расчетов за потребленную тепловую и электрическую энергию имеет свою специфику, так как сначала происходит потребление, а лишь затем оплата за потребленную энергию. Это приводит к тому, что на предприятиях энергетики возникает значительная частота кассовых разрывов, достигающая своего пика в период отопительного сезона (ноябрь-апрель). Такая особенность расчетов между энергоснабжающими организациями и потребителями приводит к возникновению как кредитного (в случае неоплаты за потребленную энергию), так и инфляционного риска. Это свидетельствует о том, что инфляционные процессы будут иметь существенное влияние на финансовое состояние энергетических предприятий.

Обеспечение бесперебойного и надежного энергоснабжения всех потребителей возможно при использовании передовой техники и технологий, что требует постоянной модернизации, реконструкции и обновления основного оборудования генерирующих источников и передающих сетей. Значительный уровень дебиторской задолженности, варьируемый по сезонам года, с одной стороны, и недостаточность собственных средств для развития, с другой стороны, приводит к нестабильному финансовому положение энергетических предприятий. Поэтому у предприятий энергетики возникает необходимость в привлечении значительных заемных средств для инвестирования. Как следствие, сильная закредитованность энергетики приводит к значительному уровню процентных рисков.

Однако отраслевую специфику предприятия необходимо учитывать не только на стадии определения рисков, но и на последующих стадиях управления рисками предприятия.

Управление рисками на уровне предприятия должно включать в себя разработку и реализацию экономически целесообразных для данного предприятия рекомендаций и мероприятий, направленных на минимизацию финансовых и материальных потерь, а также на максимизацию возможных доходов, связанных с риском.

Результативность управления вообще и управленческих решений в частности связана с комплексным использованием множества обстоятельств и во многом зависит от процедуры принятия решений, порядка и условий их практической реализации. Поэтому столь важны методологические основы при разработке и принятии решений.

В настоящее время теорией риск-менеджмента предлагаются к апробации различные модели управления рисками предприятий. Одной из классических является модель, разработанная И.А. Бланком (рисунок 1) [1]. 
Dтаны процесса уіравления

финансовыми рисками предприятия

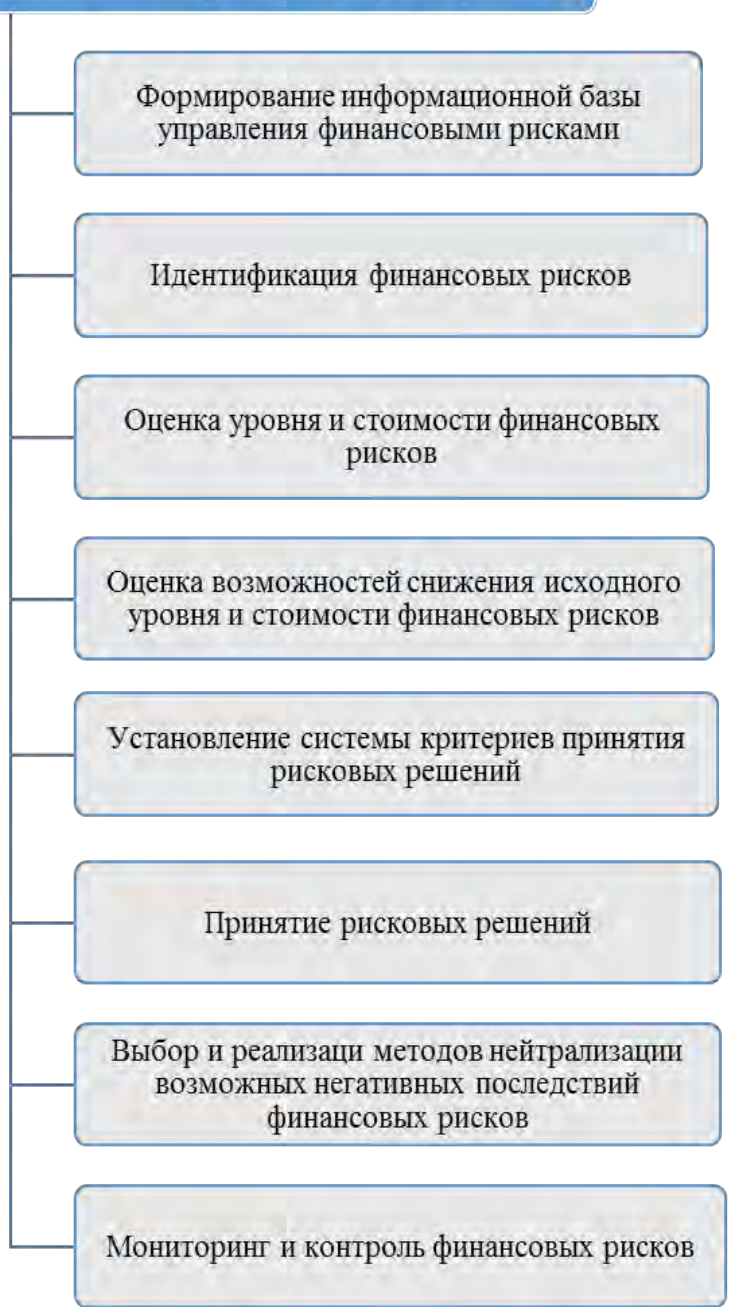

Рисунок 1 - Основные этапы процесса управления финансовыми рисками предприятия

Согласно данной модели, последовательность процесса управления финансовыми рисками включает несколько этапов:

1-й этап - формирование информационной базы управления рисками. Эффективность управления рисками предприятия во многом определяется используемой информационной базой. В зависимости от вида осуществляемой деятельности и отдельных направлений финансовой деятельности для ее формирования используются данные о динамике факторов внешней финансовой среды и конъюнктуры рынка в разрезе отдельных его сегментов, о финансовой устойчивости и платежеспособности потенциальных дебиторов - покупателей и т.д.

2-й этап - идентификация рисков. Она осуществляется в следующем порядке:

1) идентифицируются факторы риска;

2) определяются присущие систематические (рыночные) виды рисков;

3) определяется перечень несистематических (специфических) рисков;

4) формируется предполагаемый общий портфель рисков;

5) на основе портфеля идентифицированных рисков определяются сферы наиболее рисковых видов деятельности предприятия.

3-й этап - оценка уровня и стоимости рисков. Этот этап представляется наиболее сложным, требующим использования современного методического инструментария, высокого уровня технической и программной оснащенности менеджеров, а также привлечения в необходимых случаях квалифицированных экспертов. Этап оценки рисков можно разделить на несколько стадий. 
На первой стадии определяется вероятность возможного наступления рискового события по каждому виду идентифицированных рисков. С этой целью используется обширный методический инструментарий оценки, позволяющий оценить уровень этой вероятности в конкретных условиях. На этой же стадии формируется группа рисков предприятия, вероятность реализации которых определить невозможно (группа рисков, реализуемых «в условиях неопределенности»).

На второй стадии определяется размер возможного финансового ущерба при наступлении рискового события. Этот ущерб характеризует максимально возможный убыток от осуществления операции или определенного вида деятельности без учета возможных мероприятий по нейтрализации негативных последствий риска.

На третьей стадии с учетом вероятности наступления рискового события и связанного с ним возможного финансового ущерба (ожидаемых финансовых потерь) определяется общий исходный уровень риска по отдельным операциям или отдельным видам деятельности.

4-й этап - оценка возможностей снижения исходного уровня и стоимости рисков. Эта оценка осуществляется последовательно и включает следующие основные стадии:

1) определяется уровень управляемости рассматриваемых рисков;

2) изучается возможность передачи рассматриваемых рисков страховым компаниям;

3) оцениваются внутренние финансовые возможности предприятия по обеспечению снижения исходного уровня и стоимости отдельных рисков (созданию соответствующих резервных денежных фондов, оплате посреднических услуг при хеджировании рисков, оплате услуг страховых компаний и т.п.).

5-й этап - установление системы критериев принятия рисковых решений. Базируется на финансовой философии предприятия и конкретизируется с учетом политики осуществления управления различными аспектами его деятельности.

6-й этап - принятие рисковых решений. На основе оценки исходного уровня риска, возможностей его снижения и установленных значений предельно допустимого их уровня процедура принятия рисковых решений сводится к двум альтернативам - принятию риска или его нейтрализации.

7-й этап - выбор и реализация методов нейтрализации возможных негативных последствий рисков, который призван обеспечить снижение исходного уровня принятых рисков до приемлемого его значения. Процесс нейтрализации возможных негативных последствий рисков заключается в разработке и осуществлении предприятием конкретных мероприятий по уменьшению вероятности возникновения отдельных видов рисков и снижению размера связанных с ними ожидаемых финансовых потерь.

8-й этап - мониторинг и контроль рисков.

В настоящее время на базе модели И.А.Бланка, рядом ученых (Можаевой С.В., Шапкиным А.С., Тепманом Л.Н., Королевой С.Е. и др.) разработаны и иные модели управления риском $[2,3,4,5]$.

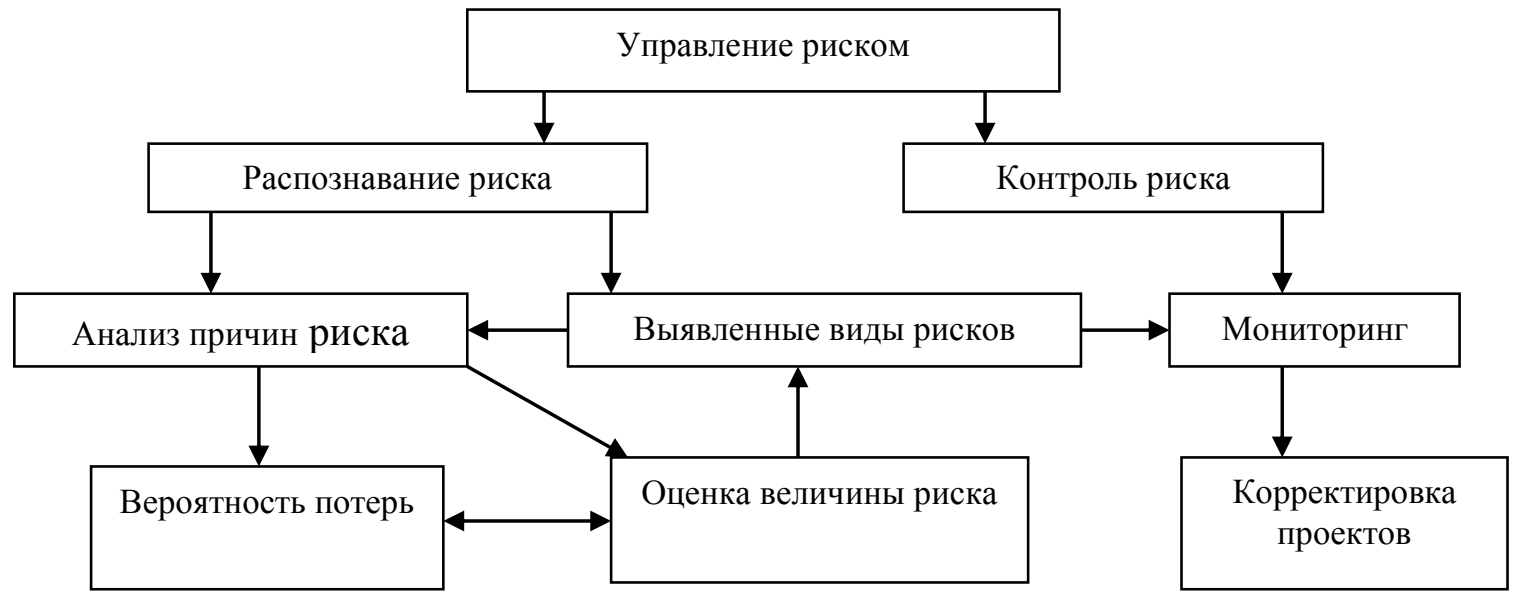

Рисунок 2 - Управление риском (автор Можаева С. В. [2]) 


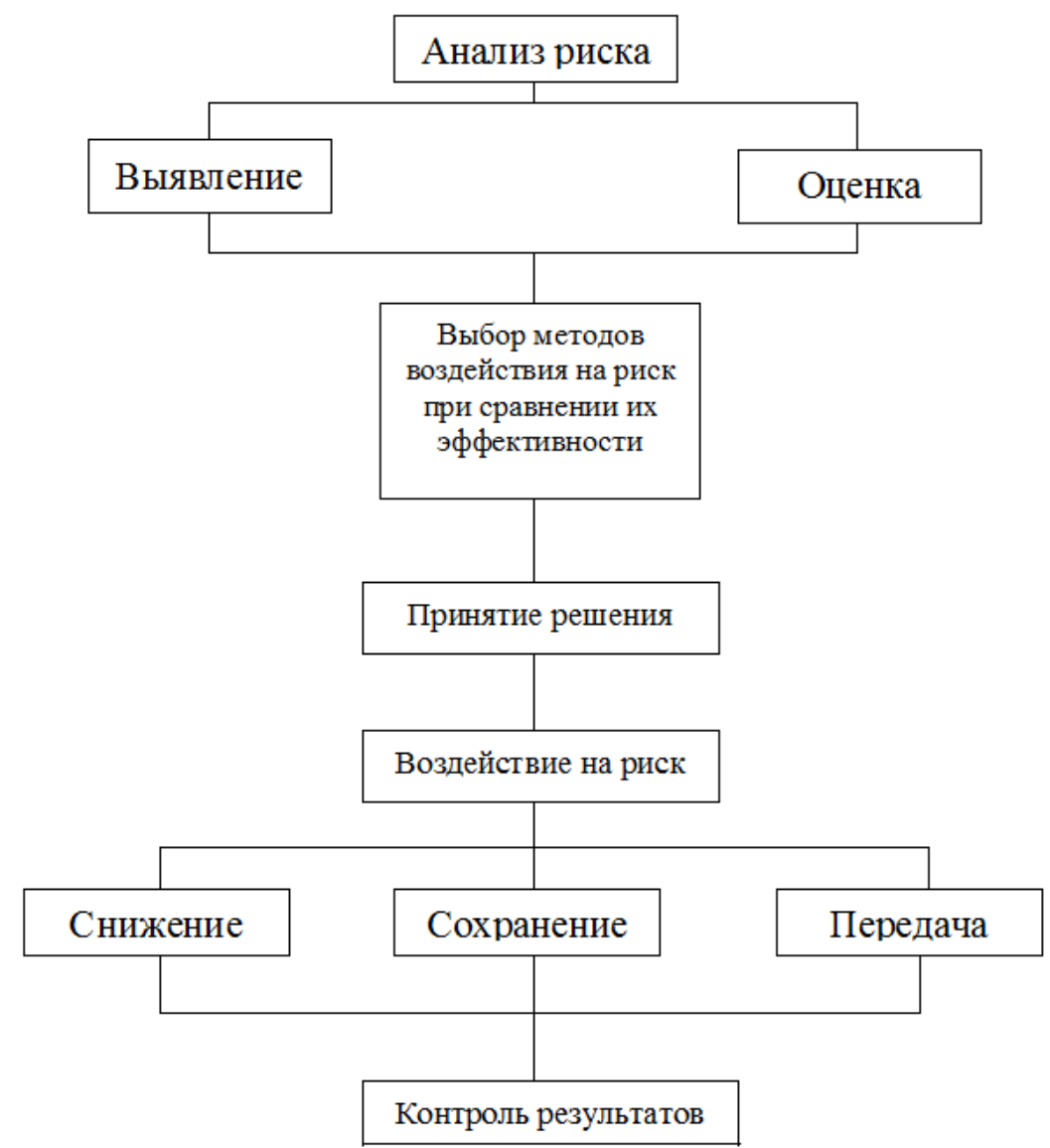

Рисунок 3 - Общая схема процесса управления риском (авторы Шапкин А.С., Шапкин В.А. [3])

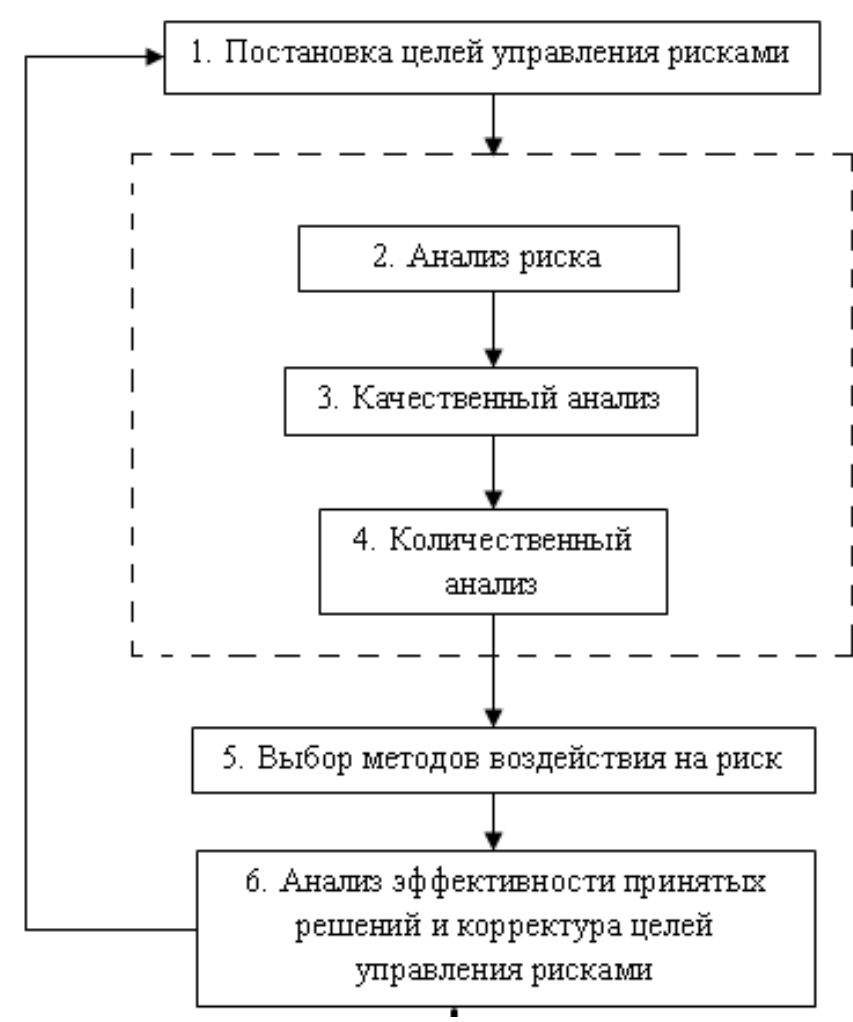

Рисунок 4 - Процесс управления рисками (авторы Тепман Л.Н., Эриашвили Н.Д. [4]) 


\section{Процесс управления \\ риском}
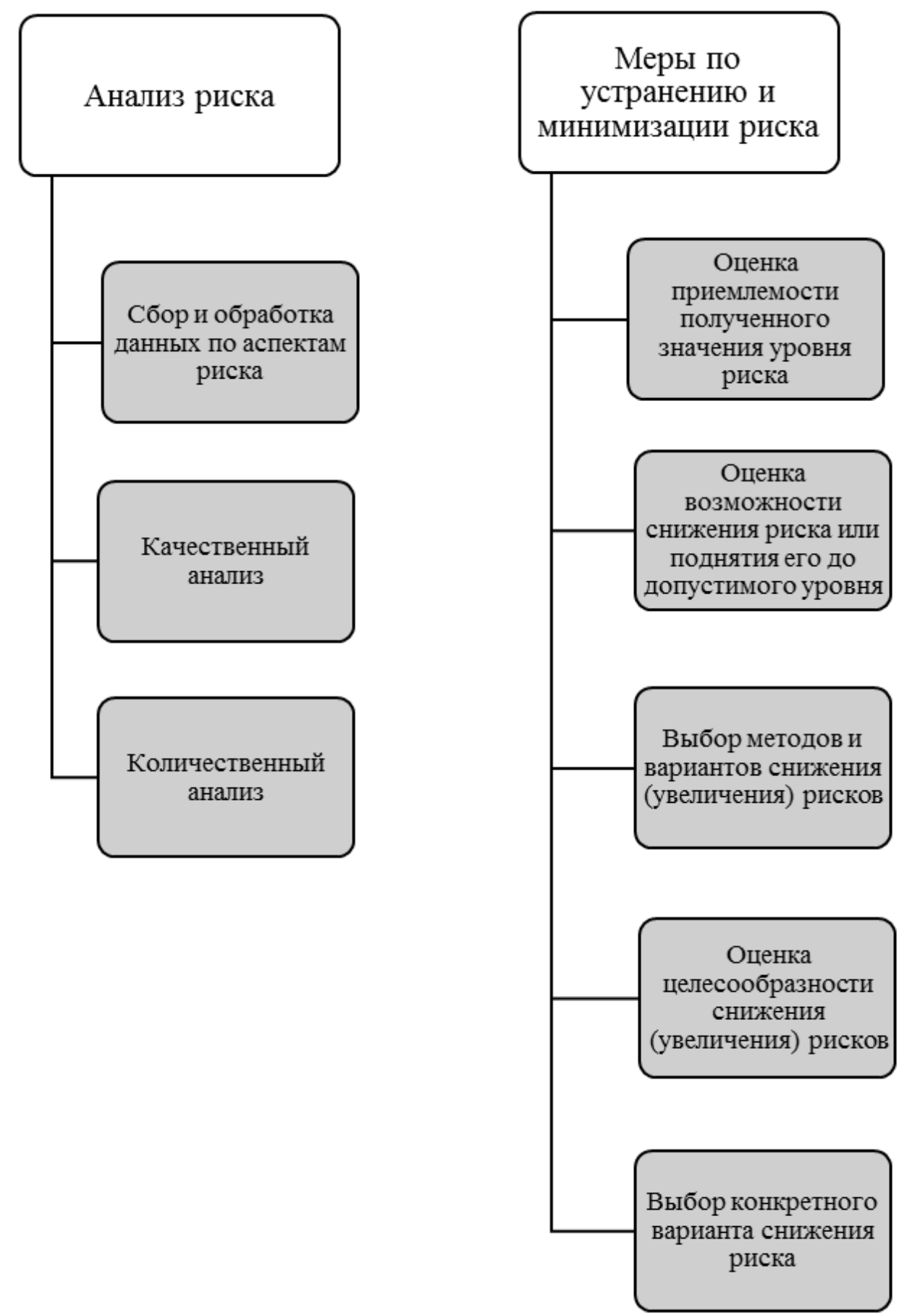

Рисунок 5 - Основные тапы процесса управления рисками (автор Королёва С.Е.

$[5])$

Каждая из этих представленных моделей имеет как общие с классической моделью этапы управления рисками, так и отличия. Проведем сравнительный анализ указанных моделей (таблица 1). 
Таблица 1 - Сравнительный анализ моделей управления рисками

\begin{tabular}{|c|c|c|c|c|c|}
\hline $\begin{array}{l}\text { Авторы } \\
\text { Этапы управления } \\
\text { рисками }\end{array}$ & $\begin{array}{l}\text { Шапкин } \\
\text { А.C. }\end{array}$ & $\begin{array}{l}\text { Можаева } \\
\text { С.В. }\end{array}$ & $\begin{array}{l}\text { Королёва } \\
\text { С.Е. }\end{array}$ & $\begin{array}{l}\text { Тепман } \\
\text { Л.Н. }\end{array}$ & $\begin{array}{l}\text { Бланк } \\
\text { И.А. }\end{array}$ \\
\hline $\begin{array}{l}\text { Формирование инфор- } \\
\text { мационной базы }\end{array}$ & - & - & + & - & + \\
\hline Идентификация рисков & + & + & + & + & + \\
\hline $\begin{array}{l}\text { Качественный анализ } \\
\text { риска }\end{array}$ & - & - & + & + & - \\
\hline $\begin{array}{l}\text { Количественный анализ } \\
\text { риска }\end{array}$ & - & - & + & + & - \\
\hline Анализ причин риска & - & + & - & - & - \\
\hline Оценка рисков & + & + & + & - & + \\
\hline $\begin{array}{l}\text { Выбор и реализация } \\
\text { методов воздействия на } \\
\text { риск }\end{array}$ & + & - & + & + & + \\
\hline $\begin{array}{l}\text { Принятие рисковых } \\
\text { решений }\end{array}$ & + & - & - & - & + \\
\hline $\begin{array}{l}\text { Анализ эффективности } \\
\text { принятых решений }\end{array}$ & - & - & + & + & - \\
\hline Мониторинг & + & + & - & - & + \\
\hline
\end{tabular}

Стоит отметить, что практически во всех моделях отсутствует первый этап классической модели И.А. Бланка, на которой формируется информационная база управления рисками. Однако данный этап является одним из самых важных в формировании процесса управления рисками, так как анализ имеющегося опыта может способствовать более грамотному анализу существующей рисковой ситуации.

Анализ причин возникновения рисков, как один из этапов, не упоминается большинством авторов $[3,4,5]$. Однако эта процедура может дать более четкую картину мест возникновения рисков, что впоследствии будет способствовать формированию конкретных мероприятий для нейтрализации негативных причин возникновения рисков.

Такие авторы как Шапкин А.С. и Можаева С.В. не акцентируют свое внимание на этапе анализа эффективности принятых решений. Однако игнорирование данного этапа впоследствии может негативно сказаться на финансовом состоянии предприятия. Для обеспечения эффективности принятия решений необходимо проводить сравнительный анализ затраченных ресурсов и эффекта от проведенных мероприятий.

Для принятия обоснованных решений по управлению рисками необходимо ввести систему критериев. Для определения масштабов риска конкретного предприятия и возможных реакций менеджеров на сложившуюся ситуацию должна быть разработана шкала и установлены допустимые пределы риска. То есть, необходимо использовать систему шкалирования и лимитирования рисков с дифференциацией по их видам.

Принимая во внимание сложившуюся практику риск-менеджмента, преимущества и недостатки известных моделей управления рисками, предлагаем авторскую модель управления рисками, которая предполагает следующую последовательность этапов:

- Формирование информационной базы управления рисками;

- Идентификация рисков;

- Анализ причин возникновения рисков;

- Оценка рисков;

- Принятие решения о необходимости воздействия на риск:

а. шкалирование рисков;

b. лимитирование рисков.

- Выбор и реализация методов воздействия на риски;

- Анализ эффективности принятых решений; 
- Мониторинг рисков.

Содержание каждого из указанных этапов управления рисков будет иметь значительные отличия в зависимости от специфики деятельности предприятия. Так, последствия и вероятность возникновения производственного риска на промышленном и торговом предприятии значительно отличаются. В связи с этим шкала для данного вида риска на указанных предприятиях будет различна.

Для предприятий энергетики целесообразно провести идентификацию рисков на каждом этапе технологического цикла. Технологический цикл производства энергии включает четыре основных этапа: генерация, передача, распределение и потребление. В результате реформ Белорусской энергетической системы будут выделены оптовый и розничный рынки энергии и мощности. В оптовый рынок войдут генерация, передача и распределение энергии. Для каждого этапа технологического цикла будут характерны различные виды рисков. При этом, чем выше этап в технологическом процессе, тем больше вероятность проявления рисков. Так, у генерирующих предприятий будут присутствовать практически все виды рисков (производственные, природные, финансовые и т.д.), тогда как при сбыте наибольшее влияние будут оказывать только спекулятивные риски. Таким образом, в энергетике целесообразно ведение учета рисков на каждой стадии технологического цикла, что позволит не только своевременно выявлять риск и определять его масштаб, но более эффективно управлять им.

\section{ВЫВОДЫ}

Современный этап развития экономики страны характеризуется нестабильностью внешней и внутренней среды. Деятельность практически всех субъектов экономики подвержена в сильной степени конъюнктурным колебаниям. Поэтому современному бизнесу необходимо быть оперативным, реагировать на меняющиеся условия рынка, быстро адаптироваться к его условиям, сохраняя при этом конкурентоспособность. Реформирование энергосистемы республики потребует создания определенных рынков. Наибольшая конкуренция должна достигаться на этапе генерации электроэнергии. По оценкам зарубежных специалистов она может составлять более 60 \%. Передача электроэнергии по магистральным линиям предполагает наличие естественной монополии ввиду использования единой сети. Распределение электроэнергии также предполагает наличие специфической инфраструктуры, то есть конкуренция на рынке практически отсутствует. Сбыт электроэнергии - это потенциальный розничный рынок. Эффективное функционирование предприятий энергетики в условиях рынка возможно при условии оперативного учета и управления возникающими рисками.

\section{ЛИТЕРАТУРА}

1. Бланк И.А. Управление финансовыми рисками. - Киев: Ника-Центр, 2005. $-600 \mathrm{c}$.

2. Можаева С.В. Экономика энергетического производства: Учебное пособие. 6-е изд., доп. и перераб. - СПб.: Издательство «Лань», 2011. - 272 с.

3. Шапкин А.С. Теория риска и моделирование рисковых ситуаций: учебник для бакалавров / А.С. Шапкин, В.А. Шапкин. - 6-е изд. - М.: Издательско-торговая корпорация «Дашков и Ко», 2014. - 880 с.

4. Тепман Л.Н. Управление рисками в условиях финансового кризиса: учеб. пособие для студенов вузов, обучающихся по направлениям экономики и управления / Л.Н. Тепман, Н.Д. Эриашвили. - М.: ЮНИТИ-ДАНА, 2014. - 295 с.

5. Королева С.Е. Управление хозяйственными рисками : пособие / С.Е. Королева, Г.В. Подгорный. - Минкс : Амалфея, 2014. - 120 с.

6. Ермасова Н.Б. Риск-менеджмент организации: учебно-практическое пособие / Н.Б. Ермасова. - М.: Издательско-торговая корпорация «Дашков и Кํ, 2012. - 380 с.

Статья поступила в редакцию 22 ноября 2015 года. 